\title{
Alterações no metabolismo de cinco genótipos de trigo com diferentes níveis de resistência ao Soil-borne wheat mosaic virus
}

\author{
Rocheli de Souza ${ }^{1}$, Jurema Schons ${ }^{1}$; Sandra Patussi Brammer ${ }^{2}$, Ariano Moraes Prestes ${ }^{1}$, Pedro Luiz Scheeren²; \\ Fernanda Nicolini-Teixeira ${ }^{1}$
}

${ }^{1}$ Faculdade de Agronomia e Medicina Veterinária, Universidade de Passo Fundo, BR 285, Km 171, Caixa Postal 611, 99001-970, Passo Fundo, RS. E-mail: rochelisouza@yahoo.com.br, schons@upf.br; ${ }^{2}$ Embrapa Trigo, BR 285, Km 174, Caixa Postal 451, 99001-970, Passo Fundo, RS. E-mail:sandra@cnpt.embrapa.br

Autor para correspondência: Jurema Schons

Data de chegada: 18/11/2004. Aceito para publicação em: 19/01/2005.

\begin{abstract}
Souza, Rocheli de; Schons,Jurema; Patussi Brammer, Sandra ; Moraes Prestes, Ariano ; Luiz Scheeren, Pedro; Nicolini-Teixeira, Fernanda. Alterations in the metabolism of five wheat genotypes with different resistance levels to Soil-borne wheat mosaic virus: Summa Phytopathologica, v.32, n.4, p.388-389, 2006.

Soil-borne wheat mosaic virus - SBWMV causes substantial economic losses to the wheat crop and can also infect a wide range of grass crops. An experiment was conducted in the experimental area of Embrapa Trigo, using five genotypes of wheat (BRS Guabiju, BRS 194, BRS 179, BR 23, and PF 980524) with different resistance levels to SBWMV. Samples were collected 45 days after emergence, and levels of sugars, proline concentration, and nitrate reductase

activity were biochemically analyzed to understand the metabolic alterations induced by SBWMV. Nitrate reductase activity was higher in asymptomatic plants, as compared to the level observed in plants with symptoms. Sugar and proline levels were higher in plants with disease symptoms than in asymptomatic plants. The results show that the metabolic changes were caused by the SBWMV in the five different genotypes used in the experiment.
\end{abstract}

Additional Keywords: Nitrate reductase, sugars, proline, SBWMV.

\section{RESUMO}

Souza, Rocheli de; Schons,Jurema; Patussi Brammer, Sandra ; Moraes Prestes, Ariano ; Luiz Scheeren, Pedro; Nicolini-Teixeira, Fernanda. Alterações no metabolismo de cinco genótipos de trigo com diferentes níveis de resistência ao Soil-borne wheat mosaic virus Summa Phytopathologica, v.32, n.4, p.388-389, 2006.

Soil-borne wheat mosaic virus - SBWMV, agente causal da virose que se caracteriza, em termos econômicos, como uma das mais importantes enfermidades da cultura de trigo, pode também infectar uma vasta gama de gramíneas. Com o objetivo de conhecer as alterações metabólicas promovidas pelo mosaico do trigo, foram analisados os teores de açúcares totais e a concentração de prolina e determinou-se a atividade da nitrato redutase. O experimento foi conduzido na área experimental da Embrapa Trigo, usando cinco genótipos de trigo (BRS
Guabiju, BRS 194, BRS 179, BR 23 e PF 980524) com diferentes níveis de resistência ao SBWMV. As determinações bioquímicas foram realizadas 45 dias após a emergência de plantas. A atividade da nitrato redutase foi mais elevada em plantas sem sintomas, quando comparada às com sintomas. Os níveis de açúcares e de prolina foram mais elevados em plantas com sintomas do que nas sem sintomas. Os resultados encontrados comprovam as alterações metabólicas promovidas pelo SBWMV nos cinco genótipos de trigo testados.

Palavras-chave adicionais: Nitrato redutase, açúcares, prolina, SBWMV.

O cultivo de trigo no Brasil é limitado por uma série de fatores, entre eles, as condições de clima e solo, pragas e doenças (9). O mosaico do trigo (Soil-borne wheat mosaic virus, SBWMV) está classificado no gênero Furovirus e caracteriza-se por ser transmitido pelo fungo do solo Polymyxa graminis Led (4). Os sintomas, em plantas de trigo, caracterizam-se por manchas de cor verde ou verde amareladas e/ou estrias paralelas, dependendo da estirpe do vírus e da cultivar utilizada (3). Os principais distúrbios causados pelo vírus na célula do hospedeiro podem ser atribuídos à indução de síntese de novas proteínas pelo hospedeiro, podendo algumas ser enzimas, aminoácidos, toxinas ou hormônios (1). A infecção viral pode provocar o aumento na concentração de açúcares nas folhas infectadas, possivelmente pela 
Tabela 1. Atividade da nitrato redutase, teores de açúcares totais e prolina em folhas de trigo com sintomas e sem sintomas do mosaico do trigo (Soil-borne wheat mosaic virus, SBWMV). UPF, Passo Fundo, RS. 2004

\begin{tabular}{|c|c|c|c|c|c|c|}
\hline \multirow[b]{2}{*}{ Genótipos } & \multicolumn{2}{|c|}{$\begin{array}{l}\text { Atividade da nitrato redutase ( } \mu \mathrm{g} \text { de } \\
\mathrm{NO}_{2}^{-} \text {formado } \mathrm{h} / \mathrm{mg} \text { de proteina) }\end{array}$} & \multicolumn{2}{|c|}{$\begin{array}{c}\text { Açúcares totais (mg de glicose/g de } \\
\text { MF) }\end{array}$} & \multicolumn{2}{|c|}{$\begin{array}{c}\text { Teores de prolina ( } \mu \text { Mol de } \\
\text { prolina/mg de MF) }\end{array}$} \\
\hline & Com sintomas & Sem sintomas & Com sintomas & Sem sintomas & Com sintomas & Sem sintomas \\
\hline BR Guabiju (MR) & B 0,288 b & A 0,584 b & A $17,40 \mathrm{~b}$ & B 12,38 b & A $2,379 \mathrm{a}$ & B $1,536 \mathrm{~b}$ \\
\hline BRS 194 (R) & В $0,199 \mathrm{~b}$ & A $0,560 \mathrm{~b}$ & A 21,96 a & A 18,03 a & B 1,623 a & B 1,571 a \\
\hline BRS 179 (MS) & A 0,644 a & A $0,703 \mathrm{~b}$ & A 20,43 a & B 14,32 b & A 1,724 a & B 1,519 a \\
\hline Trigo BR 23 (S) & B $0,189 \mathrm{~b}$ & A $0,525 \mathrm{~b}$ & A 20,75 a & B 14,64 b & A $1,834 \mathrm{a}$ & B 1,501 b \\
\hline PF 980524 (AS) & B $0,480 \mathrm{a}$ & A 1,367 a & A 17,47 b & B 15,63 b & A 1,831 a & B 1,519 b \\
\hline C.V. (\%) & & 6,5 & & 6,06 & & 93 \\
\hline
\end{tabular}

Médias seguidas da mesma letra minúscula na coluna e precedidas de mesma letra maiúscula na linha, não diferiram entre si pelo Teste de Duncan a 5\% de significância.

MR (moderadamente resistente); R (resistente); MS (moderadamente suscetível); S (suscetível); AS (altamente suscetível).

dificuldade de translocação de fotoassimilados para os outros órgãos das plantas (7).

O objetivo deste trabalho foi verificar alterações no metabolismo de plantas de cinco genótipos de trigo, infectadas com o SBWMV, através da determinação da atividade da enzima nitrato redutase (NR) e dos níveis de açúcares totais e prolina.

$\mathrm{O}$ experimento foi conduzido na área experimental da Embrapa Trigo (Passo Fundo/RS), e as análises bioquímicas foram realizadas no Laboratório de virologia vegetal da FAMV/UPF. Foram utilizados 5 genótipos de trigo (Tabela 1), com diferentes níveis de resistência ao SBWMV, e o delineamento experimental foi o de blocos ao acaso com três repetições. Em cada parcela, 45 dias após a emergência das plantas, foram coletadas plantas com e sem sintomas, sendo que a constatação da presença ou não do vírus na planta, foi baseada nos sintomas e na presença de espóros de resistência do $P$. graminis no sistema radicular. Logo, foi determinado a atividade da nitrato redutase (8), teores de açúcares totais (5) e prolina (10). Os dados foram submetidos à análise de variância e as diferenças entre as médias comparadas pelo teste de Duncan a $5 \%$.

De modo geral, as plantas sem sintomas apresentaram maior atividade da NR quando comparadas às com sintomas, destacando-se a linhagem PF 980524, altamente suscetível ao SBWMV. Estes resultados contrariam os observados em abóbora infectada com Watermelon mosaic virus, WMV e caupi infectado com Cowpea mosaic virus, CPMV (6), casos em que o autor observou maior atividade da NR em plantas infectadas.

Os níveis de açúcares totais foram mais elevados em plantas de trigo com sintomas, havendo diferenças significativas entre as duas condições, exceto no genótipo resistente (BRS 194) em que plantas sem sintomas não diferiram das sintomáticas. Estes resultados concordam com as observações de Behl \& Chowfla (2), em plantas de tomate infectadas com o Potato virus $Y$, PVY. Altos níveis de açúcares nas folhas das plantas de batata infectadas com o Potato leafroll virus, PLRV foram também observados (7).

Quanto aos teores de prolina em plantas de trigo, verificou-se que as plantas com sintomas apresentaram maior acúmulo de prolina quando comparadas às sem sintomas do SBWMV, exceção feita ao genótipo resistente no qual, às plantas com sintomas não diferiram das sem sintomas. Este resultado indica que o genótipo resistente é mais adaptado ao estresse causado pelo vírus, tendo em vista que a prolina é um aminoácido indicador de estresses bióticos e abióticos. Resultados semelhantes foram encontrados em plantas de arroz infectadas com o Rice tungro virus, RTV (6). Diversos estudos mostram alterações nas concentrações de aminoácidos após a infecção viral (6).

\section{REFERENCIAS BIBLIOGRÁFICAS}

1. Agrios, G.N. Plant diseases caused by viroses. In: Agrios, G.N. Plant Pathology. 4 ed. Califórnia: Academic Press, 1997. p. 479-508.

2. Behl, M.K.; Chowfla, S.C. Alteration In Metabolism Induced By Necrotic Strainn Of Potato Virus "Y" In Tomato Cultivars. Indian Journal of Mycology and Plant Pathology New York, v.2, p. 205-7, 1991.

3. Caetano, V.R. Mosaico do trigo trasnmitido pelo solo "wheat soilborne mosaic virus" Tobamovirus. In: OSÓRIO, E.A. Coord. Trigo no Brasil. Campinas: Fundação Cargill 1982. v.2, p.563-570.

4. Chen, J.; Wilson, T.M.A. Taxonomy of rigid rod-shaped viruses transmitted by fungi. Agronomie, Paris, v.15, p.421-426, 1995.

5. Dubois, M.; Gilles, K.A. Halmiton, J.K.; Rebers, P.A.; Smith, F. Colorimetric method for determination of sugars and related substances. Analitical Chemistry, Washington, v.28, p. 350-6, 1956.

6. Fraser, R.S.S. Biochemistry of virus-infected plants. 3 ed. New York: Research Studies, 1987. 255p.

7. Leal, N.; Lastra, R. Altered metabolism of tomato plants infected with tomato yellow virus. Physiological Plant Pathology, Palo Alto, p.1-7, 1984.

8. Mohanty, B.; Fletcher, J.S. Ammonium influence on the growth and nitrate reductase activity of paul's scarlet rose suspension cultures. Plant Physiology, Palo Alto, v.58, p.731-5, 1976.

9. Prates, L.G.; Fernandes, J.M.C Determinação da taxa de crescimento micelial de Bipolaris sorokiniana. In: Reunião Nacional de Pesquisa de Trigo, 18., 1999, Passo Fundo. Anais. Passo Fundo: Centro Nacional de Pesquisa de Trigo - Embrapa, 1999. p.481-485.

10. Torello, W.A.; Rice, L.A. Effects of $\mathrm{NaCl}$ stress on proline and cation accumulation in salt sensitive tolerance turfgrass. Plant Soil, Palo Alto, v. 93, p.241-7, 1986. 